\title{
On the Distinction Between Plasticity- and Roughness-Induced Fatigue Crack Closure
}

\begin{abstract}
SOTOMI ISHIHARA, YUYA SUGAI, and ARTHUR J. McEVILY
A series of experiments has been carried out to determine why some alloys display plasticityinduced fatigue crack closure (PIFCC), whereas other alloys display roughness-induced crack closure (RIFCC). Two alloys were studied, the aluminum alloy 6061-T6 (PIFCC) and a steel of comparable yield strength, S25C (RIFCC). The experiments included the determination of the crack-opening levels as a function of $\Delta K, d a / d N$ as a function of $\Delta K_{\mathrm{eff}}-\Delta K_{\mathrm{efft}}$, removal of the specimen surface layers, removal of the crack wake, the determination of crack front shapes, crack surface roughness profiles, and the degree of lateral contraction in the plastic zone at a crack tip. Based on crack tip opening displacement (CTOD) considerations, it is concluded that PIFCC is favored in alloys of low modulus and relatively low yield strength. In addition, a low strain-hardening rate such as for the 6061 alloy will favor PIFCC. Steels with a higher modulus and a higher strain-hardening rate than 6061 will, in general, exhibit RIFCC, even at comparable yield strength levels. In ferritic steels, the fracture surface roughness and consequently the crack-opening level will increase as the coarseness of the microstructure increases.
\end{abstract}

DOI: $10.1007 / \mathrm{s} 11661-012-1121-9$

(C) The Minerals, Metals \& Materials Society and ASM International 2012

\section{INTRODUCTION}

ACCORDING to ASTM E647, the Standard Test Method for Measurement of Fatigue Crack Growth Rates, the term crack closure refers to the phenomenon whereby the fracture surfaces of a fatigue crack come into contact during the unloading portion of a force cycle and force is transferred across the crack. In many materials, crack closure can occur while the force is above the minimum force in the cycle even when the minimum force is tensile. After reloading from the minimum force, some increment of tensile loading must be applied before the crack is fully open. It is also noted that ASTM Standard Test Procedures $982^{[1]}$ and $1343^{[2]}$ provide excellent overviews of the subject of fatigue crack closure.

In the $1970 \mathrm{~s}, \mathrm{Elber}^{[3,4]}$ introduced the important topic of fatigue crack closure into the literature and showed by means of experiments with the aluminum alloy 2024T3 (yield strength $[\mathrm{YS}]=350 \mathrm{MPa}$ ) that at a given $R$ value, the crack-opening level increased with $\Delta K$.

Similar results have been obtained with other lowand medium-strength aluminum alloys, e.g., 6061-T6 (YS $276 \mathrm{MPa}$ ) (Figure 1). ${ }^{[5]}$ This type of crack closure is referred to as plasticity-induced fatigue crack closure (PIFCC), and Elber proposed that PIFCC was caused by the residual stretch of material in the wake of

SOTOMI ISHIHARA, Professor, and YUYA SUGAI, Graduate Student, are with the Department of Mechanical Engineering, University of Toyama, Toyama 930-8885, Japan. Contact e-mail: ishi@eng.u-toyama.ac.jp ARTHUR J. McEVILY, Professor Emeritus, is with the Department of Chemical, Materials, Biomolecular Engineering, University of Connecticut, Storrs, CT 06269.

Manuscript submitted July 4, 2011.

Article published online March 23, 2012 the crack tip. Minakawa et al. ${ }^{[6]}$ and Budiansky and Hutchinson ${ }^{[7]}$ provided a mathematical analysis of plasticity-induced closure that is consistent with Elber's interpretation. However, higher strength aluminum alloys might not exhibit PIFCC, e.g., 7090-T6 (YS $650 \mathrm{MPa}$ ) and IN9021-T4 (YS $530 \mathrm{MPa}$ ).

Soon after Elber's initial studies, other forms of crack closure were found, including a type of material-related crack closure now known as roughness-induced fatigue crack closure (RIFCC). In this type of crack closure, the crack-opening level in the macrocrack range is constant and independent of the $\Delta K$ level, in contrast to PIFCC. An example of this type of RIFCC behavior is shown in Figure $2^{[6]}$ for a 6 -mm-thick $9 \mathrm{Cr}$ - 1 Mo steel(YS $530 \mathrm{MPa}$ ). Here, the $K_{\text {op }}$ level is approximately $2.5 \mathrm{MPa} \sqrt{\mathrm{m}}$.

It is also to be noted in Figure 2 that at a thickness of $0.3 \mathrm{~mm}$, PIFCC was observed. However, for a 1018 steel (YS $260 \mathrm{MPa}$ ), only RIFCC at a higher $K_{\text {op }}$ of $4.3 \mathrm{MPa} \sqrt{\mathrm{m}}$ was observed for both thicknesses (Figure 3). ${ }^{[5]}$ The variations in the $K_{\mathrm{op}}$ level for RIFCC most likely are caused by the variations in the grain size that influence the degree of roughness, in which the grain size of the 1018 steel was coarser than that of the $9 \mathrm{Cr}-1 \mathrm{Mo}$ steel. It is noted also that the effect of crack closure on the rate of fatigue crack growth is most pronounced in the near-threshold range at low $R$ levels.

Elber also introduced the concept of an effective range of the stress-intensity factor $\Delta K_{\text {eff }}$, which is defined as

$$
\Delta K_{\text {eff }}=K_{\max }-K_{\text {op }}
$$

where $K_{\mathrm{op}}$ is the stress-intensity factor at the crackopening level. For 2024-T3, he proposed that $\Delta K_{\text {eff }}$ be given by following equation:

$$
\Delta K_{\text {eff }}=(0.5+0.4 R) \Delta K
$$




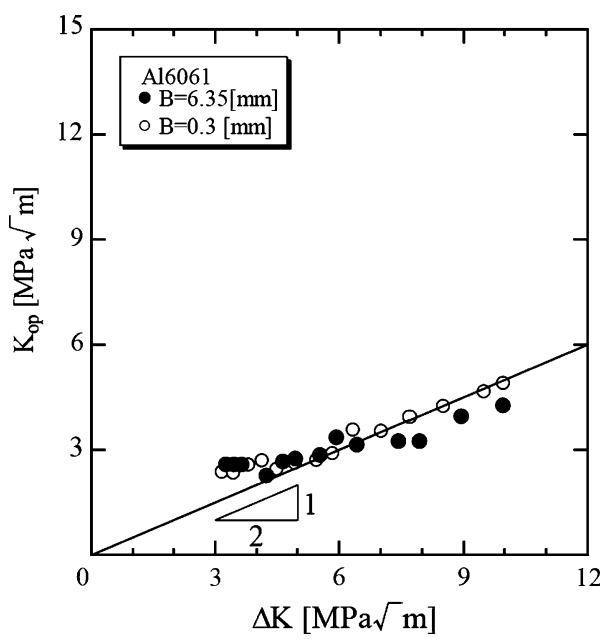

Fig. $1-K_{\text {op }}$ vs $\Delta K$ plot for 6061 aluminum alloy for two CT specimen thicknesses. ${ }^{[5]}$

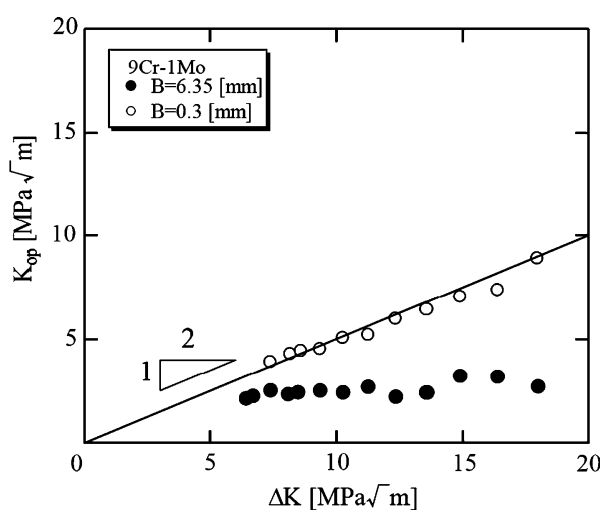

Fig. $2-K_{\mathrm{op}}$ vs $\Delta K$ plot for $9 \mathrm{Cr}-1 \mathrm{Mo}$ steel for two specimen thicknesses. ${ }^{[6]}$

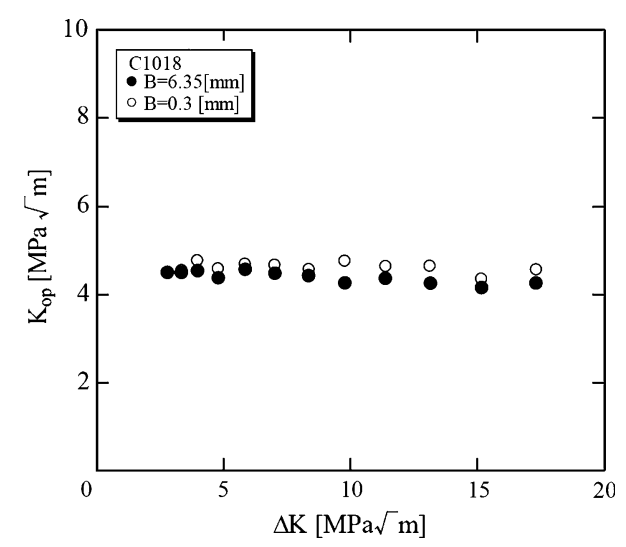

Fig. $3-K_{\text {op }}$ vs $\Delta K$ plot for $\mathrm{C} 1018$ steel for two specimen thicknesses. ${ }^{[7]}$

This relationship has been used to explain why an $R$ effect is found in fatigue crack growth. For plane-stress loading conditions, Budiansky and Hutchinson ${ }^{[7]}$ provided theoretical support for such a relationship. However, as indicated by Figure $4,{ }^{[8]}$ it is clear that at the

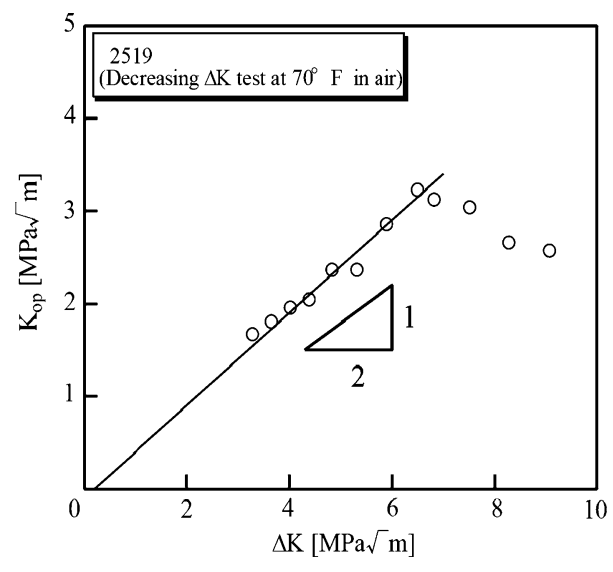

Fig. 4-The variation in $K_{\mathrm{op}}$ as a function of $\Delta K$ for the aluminum alloy $2519 .^{[8]}$

higher levels of $\Delta K$, the trend predicted by Eq. [2] is not followed. It is also known that across the thickness of a compact specimen crack, the opening level is not constant. Schivje in his review article on crack closure, ${ }^{[9]}$ for example, pointed out that at the crack-opening level in the surface, the plane stress region of a structural aluminum compact specimen is higher than in the interior plane strain region.

Although much research on crack closure has been conducted, it seems that it is unclear why some aluminum alloys exhibit PIFCC whereas steels exhibit RIFCC, although it has been suggested ${ }^{[10,11]}$ that the factors influencing the crack tip opening displacement (CTOD) may be of importance. The expression for the CTOD under plane stress conditions is

$$
\mathrm{CTOD}=\frac{\Delta K_{\mathrm{eff}}^{2}}{\sigma_{\mathrm{y}} E}
$$

Aluminum alloys with their relatively low Young's modulus compared with steel will have a CTOD three times larger than that of steel of the same yield stress level, meaning that there will be a much larger plastic stretch at the surface and a higher degree of PIFCC in the plane stress region at the surface of steel. It also follows that if PIFCC is surface related, then machining away the surface layers should decrease the PIFCC level. No such effect would be expected for RIFCC. For PIFCC, it is to be expected also that as the thickness of a compact specimen increased, the fatigue crack growth rate would increase also as the relative importance of PIFCC decreased. No such thickness effect would be expected in the case of RIFCC.

In the attempt to determine why some alloys exhibit PIFCC whereas others exhibit RIFCC, the following research program was undertaken:

(a) The determination of the crack-opening level at $R=0.1$ and $d a / d N$ as a function of $\Delta K$ and specimen thickness for the aluminum alloy 6061-T6 and for the steel S25C. The results will also be used in an assessment of the validity of a previously proposed relation based on the following CTOD considerations $^{[8]}$ : 


$$
\frac{d a}{d N}=\frac{A^{\prime}}{\sigma_{y} E}\left(\Delta K_{\mathrm{eff}}-\Delta K_{\mathrm{effth}}\right)^{2}=A\left(\Delta K_{\mathrm{eff}}-\Delta K_{\mathrm{effth}}\right)^{2}
$$

(b) The determination of the effect of machining away the surface layers on the crack-opening level.

(c) The determination of the crack front shape as a function of $\Delta K$.

(d) The determination of the stepwise removal of the crack wake on the crack-opening level.

(e) The determination of the extent of lateral contraction within the crack tip plastic zone as a function of $\Delta K$.

(f) The determination of fatigue fracture surface roughness.

\section{MATERIALS, SPECIMENS AND TESTS}

Two alloys of similar yield strengths were chosen for the test program, the aluminum alloy 6061-T6, which was expected to exhibit PIFCC, and a steel, JIS S25C, which was expected to exhibit RIFCC. The chemical compositions and mechanical properties of these alloys are given in Tables I and II, respectively. The S25C steel was in the normalized condition and had an $\alpha$-grain size of $14 \mu \mathrm{m}$.

Two types of specimens were used in the crack growth studies. One was the ASTM compact specimen ${ }^{[12]}$ and the other was the ASTM disk-shaped compact specimen. ${ }^{[13]}$

ASTM-type compact specimens ${ }^{[12]}$ with $W$ equal to $57.2 \mathrm{~mm}$ and $B$ equal to 1,3 , or $6 \mathrm{~mm}$ were used in tests of the 6061 alloy. Circular compact specimens ${ }^{[13]}$ for tests of the steel were machined from a 50-mm-diameter bar. Prior to fatigue crack growth testing, the specimen surfaces were polished using 150 - to 2000 -grit papers to facilitate the observation of cracks by means of a lowpower microscope. The crack growth tests were carried out in a servocontrolled hydraulic test system under load control at room temperature in air at $20 \mathrm{~Hz}$ at $R=0.1$. The elastic compliance method was used in the determination of the crack-opening level. Bowman et al. ${ }^{[14]}$ summarized some difficulties involved with crack closure measurements. The determination of $K_{\text {op }}$ involved using the outputs from the load-cell
(PCD-320A; Kyowa Electronic Instruments Co., Ltd., Tokyo, Japan) and a strain gauge (PCD-300B; Kyowa Electronic Instruments Co., Ltd.). For each closure determination, a strain gauge was cemented to the specimen surface at a position $2 \mathrm{~mm}$ ahead of the crack tip. A typical load-deformation plot is shown in Figure 5(a), in which the crack-opening load was determined as the load corresponding to B. However, this method does not always provide an accurate determination of the crack-opening load. Therefore, in the current study, the elastic compliance method using the subtracted strain was used to improve the sensitivity and precision of the determination of the crack-opening load. A typical load vs subtracted strain curve is shown in Figure 5(b). The crack-opening load is determined as the load corresponding to the point $\mathrm{B}^{\prime}$.

In the surface-removal experiments, a fatigue crack was propagated under a constant stress-intensity factor range $\Delta K$. After reaching the macroscopic level of fatigue crack closure $K_{\text {opmax }}$, the specimen was taken from the fatigue testing machine and $0.5 \mathrm{~mm}$ was then removed from each specimen surface using an electric discharge machine (Tape Cut Model; FANUC Corporation, Chicago, IL). The specimen surfaces were then electropolished. In electrochemical polishing, the specimen was the anode and stainless steel was the cathode. Electropolishing was conducted in an electrolyte that was kept at $343 \mathrm{~K}\left(70{ }^{\circ} \mathrm{C}\right)$. The electrolyte was composed of distilled water $(250 \mathrm{cc})$, ethanol $(380 \mathrm{cc})$, and phosphoric acid $(400 \mathrm{cc}$ ). After surface removal, the fatigue crack propagation test was resumed and the $K_{\text {opmax }}$ level was determined anew.

The crack growth data were obtained either under constant $\Delta K$, decreasing $\Delta K$, or increasing $\Delta K$ test conditions in accord with the provisions of ASTM E 647-05. ${ }^{[15]}$ The decreasing $\Delta K$ tests were conducted under the following conditions:

Table II. Mechanical Properties

\begin{tabular}{lccc}
\hline & $\begin{array}{c}\text { Yield } \\
\text { Strength } \\
(\mathrm{MPa})\end{array}$ & $\begin{array}{c}\text { Tensile } \\
\text { Strength } \\
(\mathrm{MPa})\end{array}$ & $\begin{array}{c}\text { Elongation } \\
(\mathrm{pct})\end{array}$ \\
\hline 6061-T6 & 287 & 315 & 16.4 \\
S25C & 269 & 520 & 31.0 \\
\hline
\end{tabular}

Table I. Alloy Compositions

\begin{tabular}{|c|c|c|c|c|c|c|c|c|}
\hline \multicolumn{9}{|c|}{ 6061-T6 } \\
\hline $\mathrm{Mg}$ & & $\mathrm{Si}$ & & $\mathrm{Fe}$ & $\mathrm{Ca}$ & & $\mathrm{C}$ & $\mathrm{Al}$ \\
\hline 1.0 & & 0.6 & & 0.2 & 0.2 & & 0.1 & balance \\
\hline \multicolumn{9}{|c|}{$\mathrm{S} 25 \mathrm{C}$} \\
\hline $\mathrm{C}$ & $\mathrm{Si}$ & & $\mathrm{Mn}$ & $\mathrm{P}$ & $\mathrm{S}$ & $\mathrm{Ca}$ & $\mathrm{Te}$ & $\mathrm{Fe}$ \\
\hline 0.2 & 0.1 & & 0.5 & 0.01 & 0.01 & 0.1 & 0.14 & balance \\
\hline
\end{tabular}




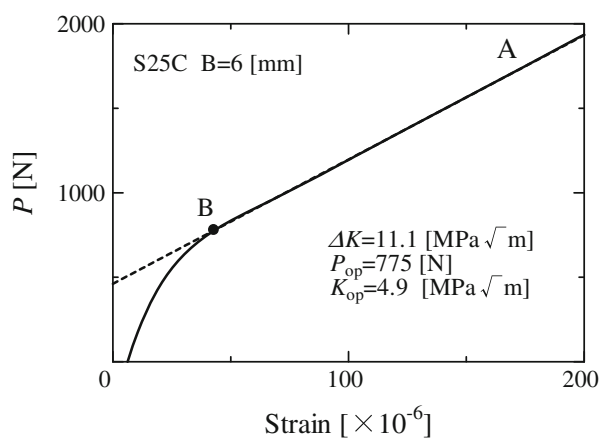

(a) Load vs. strain plot

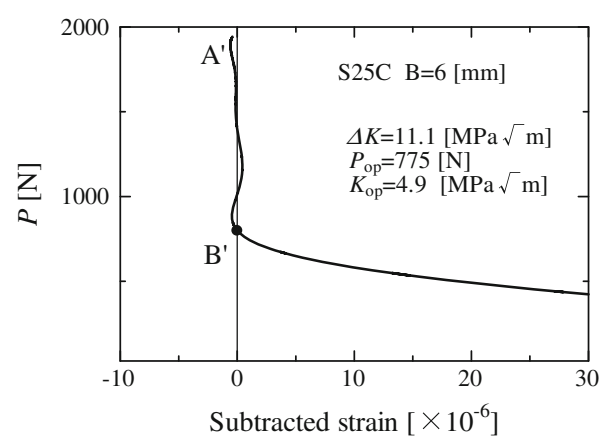

(b) Load vs. subtracted strain plot.

Fig. 5-A typical load vs subtracted deformation plots.

$$
\begin{aligned}
& (1 / K) \cdot(d K / d a)=(-0.02 \sim-0.04) \mathrm{mm}^{-1}> \\
& \quad-0.08 \mathrm{~mm}^{-1} \text { for the } 6061 \text { alloy } \\
& (1 / K) \cdot(d K / d a)=(-0.04 \sim-0.07) \mathrm{mm}^{-1}> \\
& -0.08 \mathrm{~mm}^{-1} \text { for the } \mathrm{S} 25 \mathrm{C} \text { steel }
\end{aligned}
$$

When comparisons were made between the 6061 alloy and the S25C steel, the comparisons were made at similar $d a / d N$ levels, i.e., $10^{-9} \mathrm{~m} /$ cycle. As a consequence, the $\Delta K$ levels for the steel were higher than those for the aluminum alloy.

\section{TEST RESULTS AND DISCUSSION}

\section{A. $K_{\text {op }}$ as a Function of $\Delta K$ at $R=0.1$}

Figure 6(a) is a plot of $K_{\text {op }}$ as a function of $\Delta K$ for 6061. Consistent with PIFCC, the $K_{\text {op }}$ level increases with $\Delta K$ as in Figure 1. It is also noted that the closure level increases with decreasing specimen thickness. Figure 6(b) is a similar plot for the S25C steel. For this material, the crack-opening level is independent of the $\Delta K$ level and the thickness. Both of these characteristics are typical of RIFCC.

\section{B. Effect of Surface Removal}

In a previous work ${ }^{[16]}$ that involved the effect of an overload on the subsequent fatigue crack growth behavior, it was shown that the removal of $0.5 \mathrm{~mm}$ from each

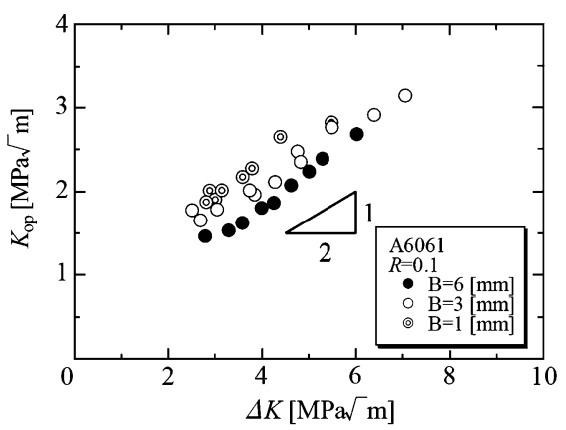

(a) For 6061-T6.

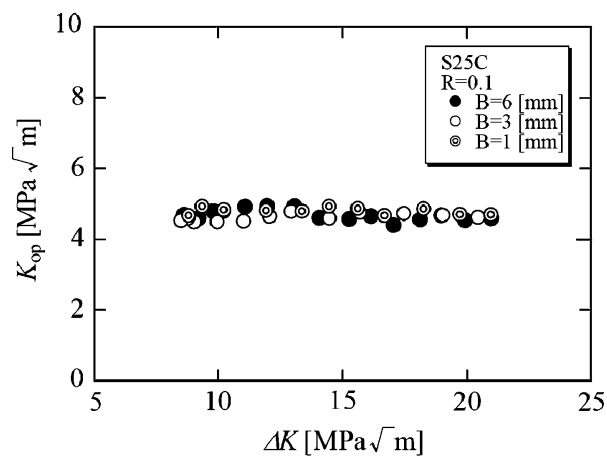

(b) For S25C steel

Fig. 6-The dependence of $K_{\mathrm{op}}$ on $\Delta K$ and specimen thickness.

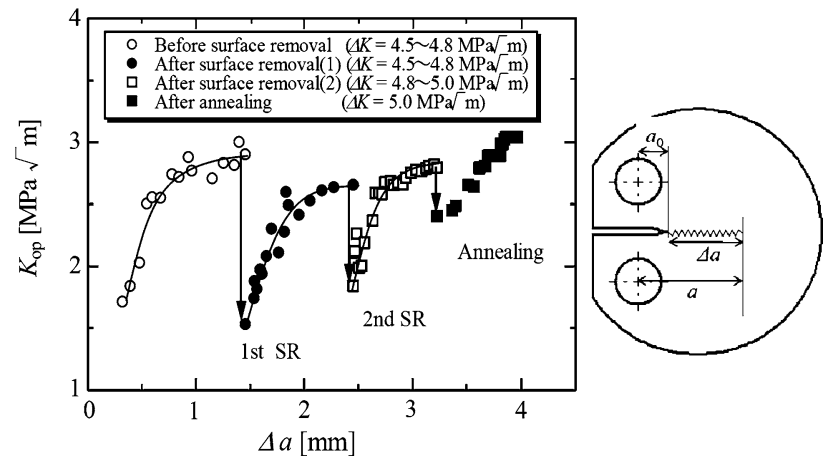

Fig. 7-Effect of surface removal (SR) on 6061 .

surface of a compact specimen immediately after the overload resulted in the elimination of much of the effect of the overload. It was, therefore, concluded that the retardation from an overload was largely caused by an enhanced level of surface-related PIFCC as the result of the overload. In the current study, we repeated this type of surface-removal experiment but without any overload involved.

Figure 7 shows the effect of surface removal on the crack-opening level of 6061. The specimen had been tested at a $\Delta K$ level of 4.5 to $5.0 \mathrm{MPa} \sqrt{\mathrm{m}}$. During each surface-removal step, $0.5 \mathrm{~mm}$ was removed from each specimen surface by electrodischarge machining, after which the surfaces were electropolished. These results show a marked effect of surface removal on the crackopening level of 6061 and indicate that the crack closure level at the surface was at least $1 \mathrm{MPa} \sqrt{\mathrm{m}}$ higher than 

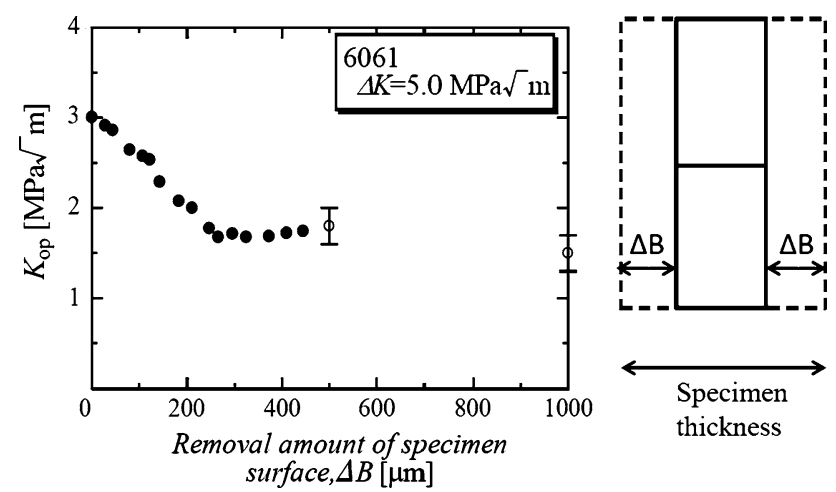

Fig. 8-Effect of stepwise surface removal on the $K_{\text {op }}$ level in 6061 cycled at 5.0 MPa $\sqrt{\mathrm{m}}$.

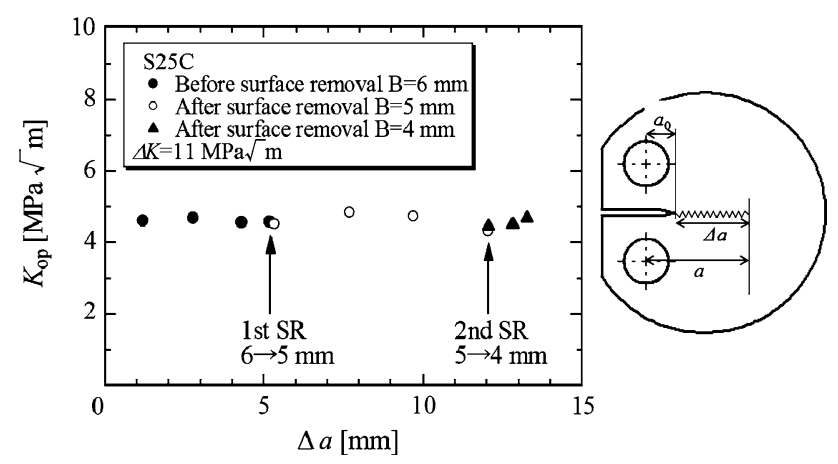

Fig. 9-Effect of surface removal (SR) on S25C.

that of the interior crack-opening level. Because 6061 exhibits PIFCC, ${ }^{[5]}$ we conclude that the plane-stress plastic zone at the specimen surface is an important factor in PIFCC. It is noted that annealing at $673 \mathrm{~K}$ $\left(400{ }^{\circ} \mathrm{C}\right)$ for 0.5 hours resulted in decrease in the surface crack-opening level. This effect might come about from a compression creep in the contact areas in the surface region.

Figure 8 shows the effect of stepwise removal by electropolishing of approximately $30 \mu \mathrm{m}$ in each step from each specimen face of a 6-mm-thick specimen that had been cycled at a $\Delta K$ of $5 \mathrm{MPa} \sqrt{\mathrm{m}}$. After $300 \mu \mathrm{m}$ of material had been removed from each the surface, PIFCC was eliminated and only RIFCC remained. The $K_{\text {op }}$ level for RIFCC was $1.5 \mathrm{MPa} \sqrt{\mathrm{m}}$, which is approximately half of the PIFCC level.

Figure 9 shows the effect of surface removal on the $K_{\text {op }}$ level for S25C, which had been cycled at $11 \mathrm{MPa} \sqrt{\mathrm{m}}$. Characteristic of RIFCC, surface removal has little if any effect on the $K_{\mathrm{op}}$ level as determined by the strain-gauge method. However, previous work, ${ }^{[17]}$ which made use of the replica technique, has shown that even in the case of RIFCC, a small amount of PIFCC exists at the surface that is not detected by the straingauge technique. The crack-opening level at the surface is always higher than in the interior.

\section{Effect of Crack Wake Removal}

In these experiments, a fatigue crack was grown at a $\Delta K$ level of $6.3 \mathrm{MPa} \sqrt{\mathrm{m}}$ in $6061-\mathrm{T} 6$ and at $11 \mathrm{MPa} \sqrt{\mathrm{m}}$ in

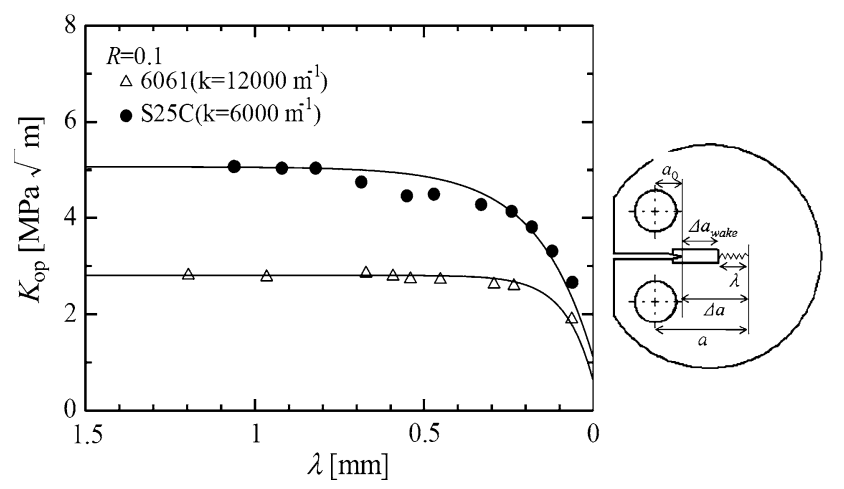

Fig. 10-The effect of wake removal on $K_{\mathrm{op}}$, the curves are in accord with Eq. [5]. $\lambda=$ wake length - amount of wake removed.

S25C. The crack wake was then removed in steps of approximately $0.1 \mathrm{~mm}$ to determine the $K_{\text {op }}$ level a function of distance from the crack tip. (This procedure is the reverse of the procedure in which crack closure was developed as an initially closure-free crack grew.) The crack-wake removal process was carried out by using an electric discharge machine (Tape Cut Model; FANUC Corporation). The thickness of the slit created in the wake removal process was approximately $1 \mathrm{~mm}$.

The results of these tests are shown in Figure 10. It is noted that the experimentally determined values for $K_{\mathrm{op}}$ can be expressed as follows:

$$
K_{o p}=\left(1-e^{-k \lambda}\right)\left(K_{\mathrm{op} \max }-K_{\min }\right)+K_{\min }
$$

where $K_{\mathrm{op}}$ is the transient value of the opening level, $k$ is a material constant that governs the rate of crack closure development, $\lambda$ is the distance in this case measured back from the crack tip, and $K_{\text {opmax }}$ is the crack-opening level associated with a crack of macroscopic length. It is noted that the values for $\mathrm{k}$ of $12,000 \mathrm{~m}^{-1}$ for 6061 and $6000 \mathrm{~m}^{-1}$ for $\mathrm{S} 25 \mathrm{C}$ are consistent with the values obtained in prior investigations, ${ }^{[18-20]}$ which were obtained under increasing $\lambda$ conditions. The wake-removal procedure provides an alternative means for the determination of the magnitude of the material constant $\mathrm{k}$.

We note that $K_{\mathrm{op}}$ is the integral of the effects of crack closure between the crack tip and the $\lambda$ value at which $K_{\text {op }}$ is determined. $K_{\text {op }}$ does not increase with increase in $\lambda$ beyond the point at which $K_{\text {opmax }}$ is reached. That is, because of the wedging effect of the crack closure developed up to the point of $K_{\text {opmax }}$, the opposing crack surfaces do not make contact beyond the $\lambda$ value associated with $K_{\text {opmax }}$. During the uploading process, as the load is applied, the crack begins to open at a $\lambda$ value corresponding to the $\lambda$ value at which $K_{\text {opmax }}$ is developed. As the load continues to increase, the value of $\lambda$ continues to decrease until the crack tip itself is open at a $\Delta K$ value corresponding to $K_{\text {opmax. }}$ During unloading, this process is reversed.

It is noted that fatigue striations range in spacing from 0.1 to $10 \mu \mathrm{m}$. They are created cycle by cycle in the plane strain region at the crack tip by localized crack tip opening and closing plastic deformation processes at $\Delta K$ 
levels above $K_{\text {op. }}$ Therefore, crack closure is not involved in the process of striation formation.

\section{Determination of the Shape of the Crack Fronts, Fracture Surface Roughness, and Lateral Contraction}

Figure 11 provides macroscopic views of the shape of the crack front in (1) the 6061-T6 aluminum alloy and (2) the $\mathrm{S} 25 \mathrm{C}$ alloy. The angle $\theta$ is the angle in the fracture surface between the specimen surface and tangent to the crack front at the specimen surface. Prior to the crack-shape observations, the cracks were grown (1.5 mm or more) at constant $\Delta K$ levels so that the rates of the fatigue crack growth were constant. It can be observed that because of a higher degree of PIFCC in the aluminum alloy at a stress-intensity range of $10 \mathrm{MPa} \sqrt{\mathrm{m}}$, the curvature of the crack front at the surface is more pronounced in the case of the aluminum alloy than for the steel.

Figure 12 indicates that as the $\Delta K$ level increased, the curvature at the surface also increased for the aluminum alloy, but it remained constant for the steel.

Figure 13 shows examples of the extent of lateral contraction in the crack-tip plastic zone after off loading for (1) 6061 and (2) S25C. The inset in Figure 13 provides information on the location of the traverse through the plastic zone. The extent of lateral contraction (dimple depth) of the plastic zone at the crack tip was determined after off-loading. The dimple depth was determined at a location $1 \mathrm{~mm}$ ahead of the crack tip

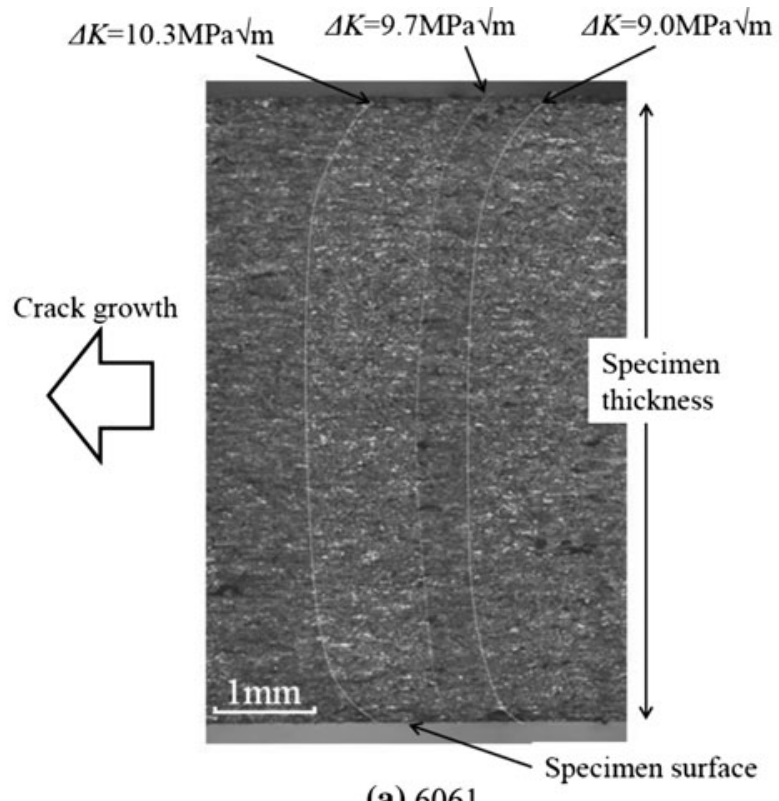

(a) 6061

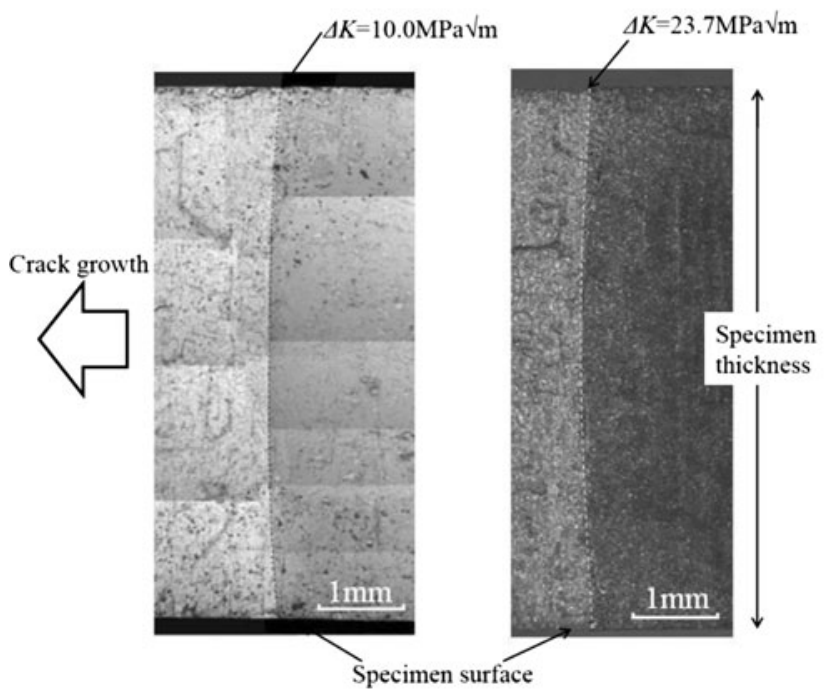

(b) $\mathrm{S} 25 \mathrm{C}$

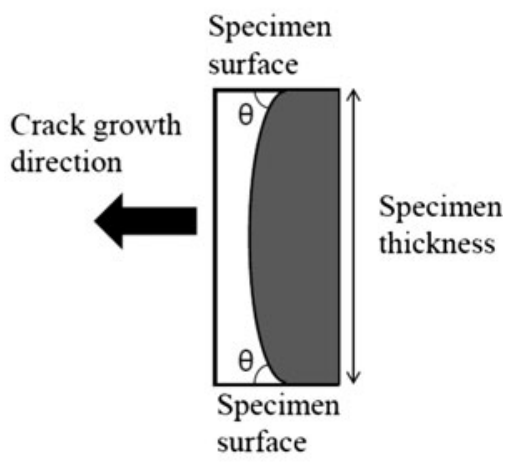

Specimen

Specimen

Fig. 11-Macroscopic views of the shape of the crack front: (a) 6061 at approximately $10 \mathrm{MPa} \sqrt{\mathrm{m}}$ and (b) the S25C steel alloy at 10 and $24 \mathrm{MPa} \sqrt{\mathrm{m}}$. 

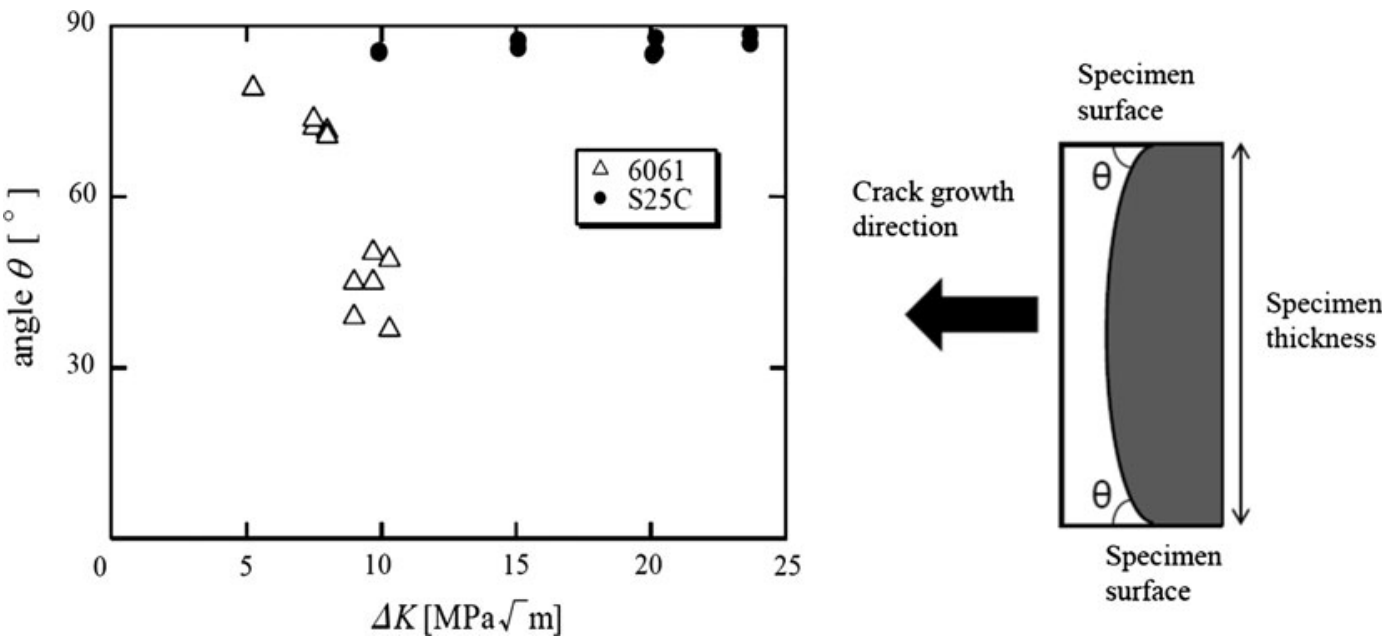

Fig. 12-Variation of the curvature at the surface as a function of $\Delta K$ for both 6061 and S25C steel.

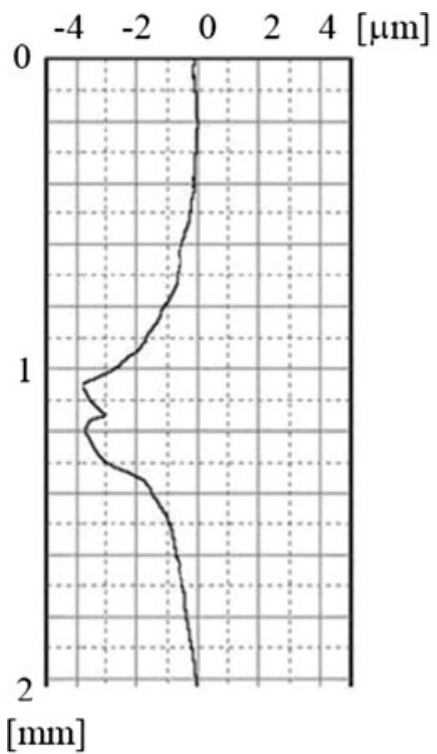

(a) 6061

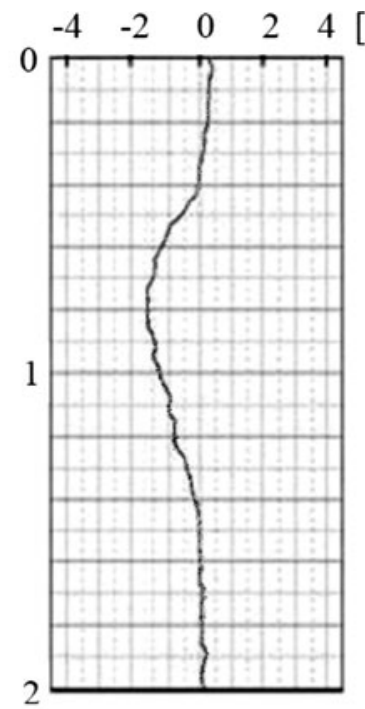

$[\mathrm{mm}]$
Measurement position
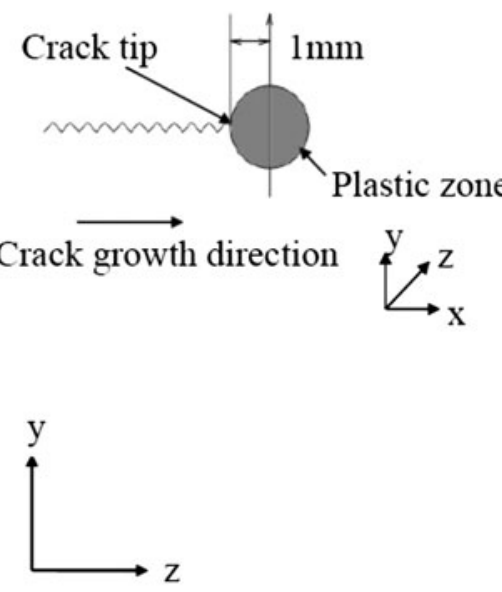

Fig. 13-Lateral contraction of the specimens: (a) $6061(\Delta K=4.8 \mathrm{MPa} \sqrt{\mathrm{m}})$ and $(b) \mathrm{S} 25 \mathrm{C}(\Delta K=15 \mathrm{MPa} \sqrt{\mathrm{m}})$.

using a stylus-type roughness meter (SURFCOM1500DX; Tokyo Seimitsu Co., Ltd., Tokyo, Japan).

It is observed that at a $\Delta K$ of $4.8 \mathrm{MPa} \sqrt{\mathrm{m}}$ in the aluminum alloy, the degree of lateral contraction is higher than for the steel at $15 \mathrm{MPa} \sqrt{\mathrm{m}}$. This contraction is responsible for PIFCC. The longitudinal extension and the lateral contraction at the crack tip that occur during loading and is a constant-volume, plastic-deformation operation in which the atoms from the surface are moved to subsurface regions of the specimen. As a result, more atoms are in subsurface planes that are parallel to the surface than were present initially. During unloading, these extra atoms give rise to PIFCC as the crack wake develops, i.e., this residual plastic wake is described by Elber. But we make the distinction that PIFCC is a surface phenomenon, not a through-thickness phenomenon, as demonstrated Figure 7. Figure 13 also indicates that PIFCC will be higher in 6061 than S25C steel because of the higher degree of lateral contraction at a given $\Delta K$ level. Because of a higher strain hardening rate in the steel, the lateral contraction process is more diffuse in the steel compared with the aluminum alloy.

One might also expect that the extent of PIFCC should increase with increasing $\Delta K$ level. This is certainly the case for the aluminum alloy 6061. However, there is no such indication of PIFCC for the S25C steel for $\Delta K$ levels used in this investigation that ranged up to approximately $20 \mathrm{MPa} \sqrt{\mathrm{m}}$. 


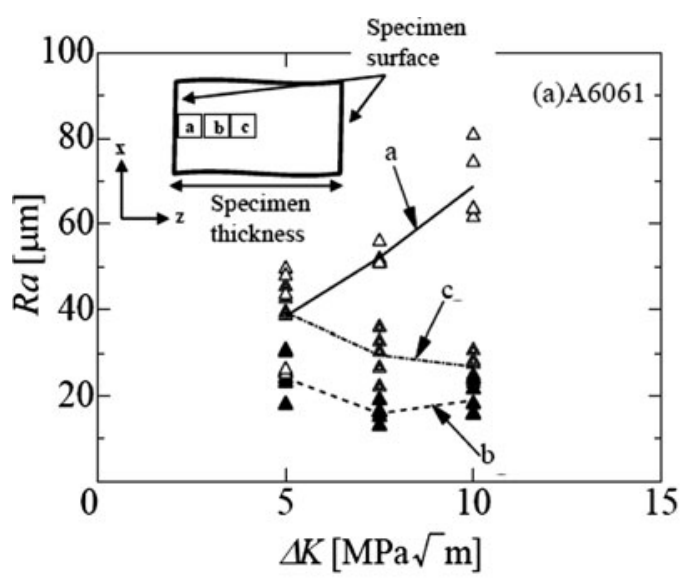

(a) A6061

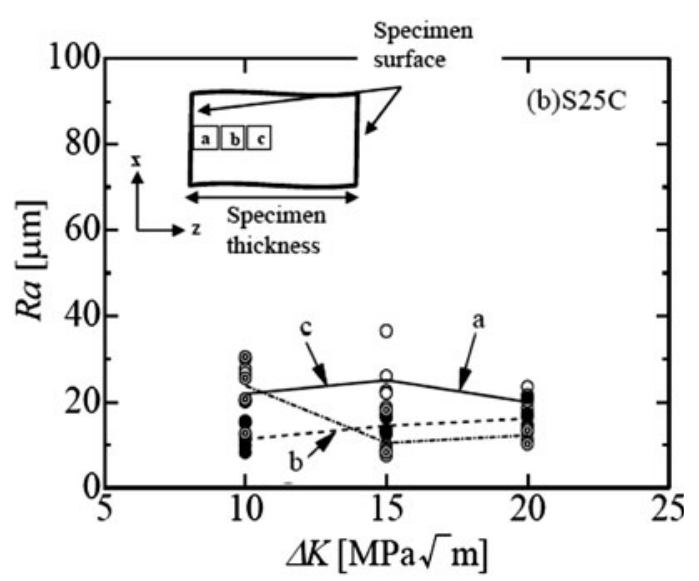

(b) $\mathrm{S} 25 \mathrm{C}$

Fig. 14-Fatigue fracture surface roughness values as a function of $\Delta K$ and location: (a) 6061-T6 and (b) S25C.

\section{E. Fracture-Surface Roughness}

A series of pictures of the fracture surfaces of selected specimens, 40 in all, were taken using an optical microscope (BX51M; Olympus Corporation, Center Valley, PA). In this series, the distance between the fracture surface and the objective lens was changed in steps of 1 to $2 \mu \mathrm{m}$. Image synthesis software (WinRoofDynamic Eye REAL; Mitani Corporation, Tokyo, Japan) was used to make a contour map of the fracture surface using these images. The roughness of the fracture surface was then determined using the WinRoof-3D Measurement software program (Mitani Corporation).

The results of the roughness determinations are shown in Figure 14. Figure 14(a) is for 6061-T6, and Figure 14(b) is for the S25C steel. In the case of 6061, it is noted that the roughness is always highest at the surface and that it increases markedly in the interval from 5 to $10 \mathrm{MPa} \sqrt{\mathrm{m}}$, which is a reflection of surfacerelated PIFCC. For S25C, the roughness is highest at the surface, but no increase is observed in the roughness level in the $\Delta K$ interval from 10 to $20 \mathrm{MPa} \sqrt{\mathrm{m}}$, which is consistent with RIFCC.

The following provides a summary of this section:

(a) In the case of plasticity-induced closure, the curvature of the crack front increases with $\Delta K$, whereas the curvature in the case of roughness-induced closure is independent of $\Delta K$. The roughness levels for the aluminum alloy were higher than for the steel.

(b) The lateral contraction in the plastic zone at the crack tip is greater in the case of plasticity-induced closure than for roughness-induced closure. This is consistent with a higher CTOD in the case of the aluminum alloy and considerations of constancy of volume during plastic deformation.

For the 6061, the closure level is observed to decrease dramatically with surface removal, but after $1 \mathrm{~mm}$ of additional crack growth, the closure level is nearly the same as before machining.

\section{F. Fatigue Crack Growth}

A main conclusion reached as a result of this study is that PIFCC is a plane-stress, surface-related event, whereas RIFCC is a plane-strain, through-thickness event. Therefore, it is to be expected that as the thickness of the test specimen of 6061-T6 aluminum alloy (PIFCC) is increased, the rate of fatigue crack growth at a given $\Delta K$ level will increase. This trend has been observed already in the case of the delay effect associated with overloads for both aluminum and steel alloys, which is known to be caused by PIFCC.

Broek and Schijve ${ }^{[21]}$ found that the crack growth rate in Al 2024-T3 increased as the thickness increased from 0.6 to $4 \mathrm{~mm}$, which is consistent with PIFCC. Lindley and Richards ${ }^{[22]}$ found that for a low-carbon steel at low values of $\Delta K$, there was no effect of thickness $(0.6$ to $7.7 \mathrm{~mm})$ on the crack growth rate, which is consistent with RIFCC. Matsuoka and Tanaka ${ }^{[23]}$ found that for the aluminum alloy A5083, the rate of fatigue crack growth increased as the specimen thickness increased from 4 to $30 \mathrm{~mm}$. They observed a similar trend, somewhat surprisingly, for HT80 steel for thicknesses ranging from 2 to $18 \mathrm{~mm}$. It is also noted that for crack growth rates above $10^{-8} \mathrm{~m} /$ cycle, Rhodes and Radon ${ }^{[24]}$ observed a similar thickness effect in an aluminum alloy, but in their case, the effect was attributed to a decrease in fracture toughness with increase in thickness, which they postulated would lead to an increase in growth rate at high growth rate levels.

The fatigue crack growth rates as a function of $\Delta K$ and also of $\Delta K_{\text {eff }}$ obtained in the current study are shown in Figures 15(a) through (d) for both alloys. As shown in Figure 15(a), for 6061, there is an effect of thickness on the rate of fatigue crack propagation, as expected for PIFCC, but as shown in Figure 15(b), there is no thickness effect on the rate of fatigue crack propagation as expected for RIFCC. For both materials, the growth rate is observed to be a single-valued function of $\Delta K_{\text {eff }}$ (Figure 15(c)). It is considered that the effect of thickness on 6061 is associated in this instance with PIFCC. In Figure 15(d), the data are plotted as a function of $\Delta K_{\text {eff }}-\Delta K_{\text {effth }}$ in accord with Eq. [4]. Note 


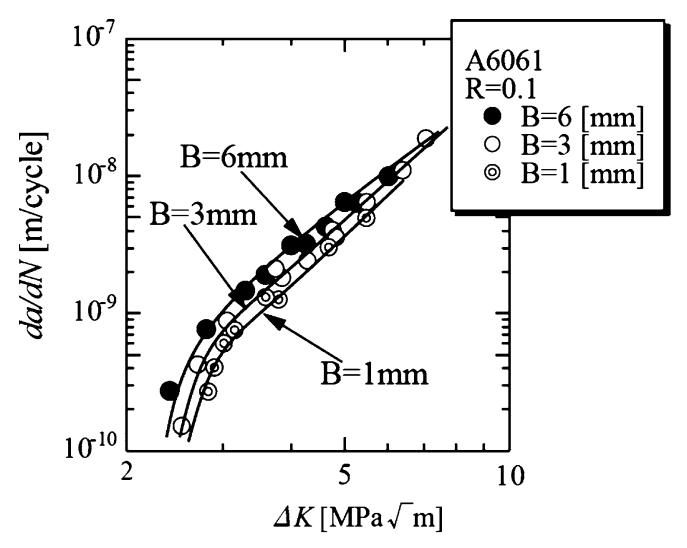

(a)

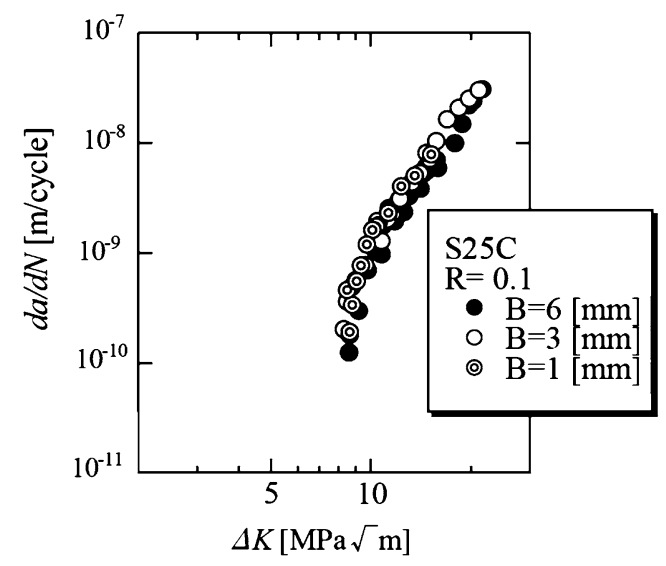

(b)

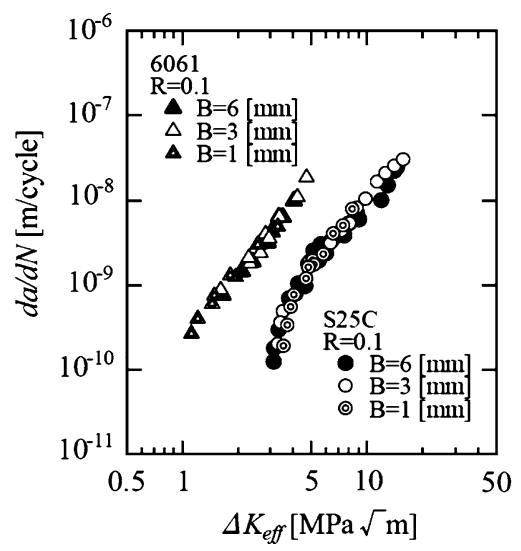

(c)

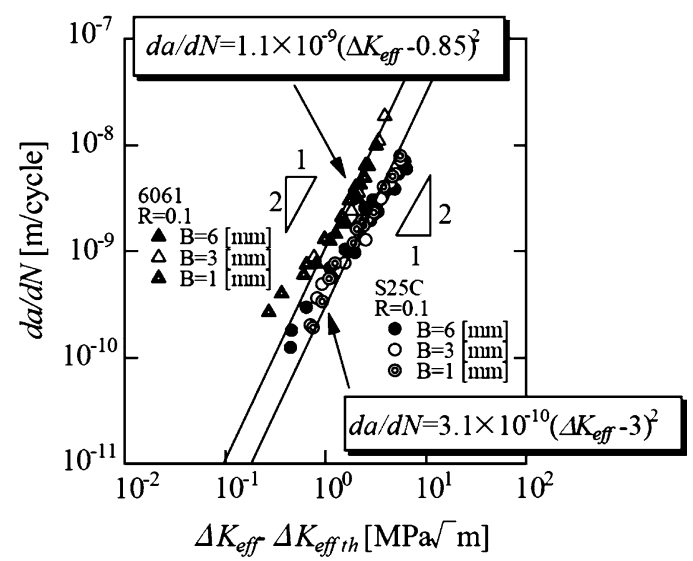

(d)

Fig. 15-(a) $d a / d N$ for 6061 as a function of $\Delta K$. (b) $d a / d N$ for S25C as a function of $\Delta K$. (c) Comparison of $d a / d N$ for both alloys as a function of $\Delta K_{\text {eff. }}(d) d a / d N$ for both alloys as a function of $\left(\Delta K_{\text {eff }}-\Delta K_{\text {effth }}\right)$. Note that the slope is 2.0 for both alloys.

that the slope of the lines is 2.0 , as expected. It can be concluded that the characterization of the rate of fatigue crack growth as a dimensionally correct function of the CTOD corrected for the threshold effect, works out well.

The expressions for the rate of fatigue crack growth in each alloy are as follows:

$\frac{d a}{d N}=1.1 \times 10^{-9}\left(\Delta K_{\text {eff }}-0.85\right)^{2}, \mathrm{~m} /$ cycle for 6061 , and

$\frac{d a}{d N}=3.1 \times 10^{-10}\left(\Delta K_{\mathrm{eff}}-3.0\right)^{2}, \mathrm{~m} /$ cycle for $\mathrm{S} 25 \mathrm{C}$

\section{FURTHER DISCUSSION}

In this study, it has been shown that PIFCC is a surface-related process associated with the crack tip plastic zone. The fact that the rates of fatigue crack propagation can be expressed as in Eqs. [6] and [7] suggests that the CTOD plays an important role in the crack growth process. All alloys will undergo both
PIFCC as well as RIFCC. However, in any given case, one or the other will be dominant. For example, in the case of a 6.35-mm-thick compact tension specimen of a 9Cr-2Mo alloy, a back-face strain gauge detected only RIFCC. However, when a replication technique was used to determine the crack-opening level, it was found that the crack-opening level was higher than that obtained by the strain-gauge method. ${ }^{[25]}$ As shown in Figure 2 for a similar alloy, this type of alloy at the $6.35-\mathrm{mm}$ thickness level exhibits RIFCC. In this case, the volume of material involved in PIFCC is too small to influence the closure process. This trend is also observed in overload tests. It has been shown that the overload retardation effect is associated strongly with PIFCC, but as the specimen thickness is increased, the extent of retardation is decreased. ${ }^{[26]}$ It has been shown also that two opening levels are associated with an overload test, the lower one of which occurs in the plane strain region of the specimen and the higher of which occurs in the plane stress region at the surface of the specimen. ${ }^{[27,28]} \mathrm{It}$ is reasonable to conclude that there are always two opening levels, even in constant amplitude loading. However, only if the volume of material involved in the surface opening process is sufficiently large, as in the case of the 6061 aluminum alloy, will PIFCC be evident. 
It is also noted that as shown in Figures 2 and 3, for a specimen thickness of $0.3 \mathrm{~mm}$, the $9 \mathrm{Cr}-1 \mathrm{Mo}$ alloy exhibits PIFCC whereas the 1018 steel exhibits RIFCC. The alpha grain size of the 1018 steel is much coarser than that of the 9Cr-1 Mo alloy, and as a result, the fracture surface of the 1018 steel is much rougher than for the $9 \mathrm{Cr}-1 \mathrm{Mo}$ steel. This greater roughness leads to RIFCC for the 1018 steel even at the $0.3-\mathrm{mm}$ thickness, whereas at the same thickness, PIFCC occurs in the 9Cr-1Mo steel. At larger thicknesses, both steels exhibit RIFCC.

Based on Figures 7 and 8, the level of RIFCC in the 6061-T6 alloy is approximately $1.5 \mathrm{MPa} \sqrt{\mathrm{m}}$, whereas for $\mathrm{S} 25 \mathrm{C}$ it is three times higher at about $4.5 \mathrm{MPa} \sqrt{\mathrm{m}}$. Figure 14 shows that the level of fracture surface roughness away from the side-surface is similar in both 6061 and S25C. Therefore, it seems that the difference in RIFCC for the two alloys might be related to the difference in their Young's moduli, but this aspect of the current study is in need of subsequent investigation.

Because $K_{\text {opmax }}$ in 6061 is $0.5 \Delta K$, below a $\Delta K$ of 9.0 $\mathrm{MPa} \sqrt{\mathrm{m}}$, the PIFCC level in 6061 will be less than the RIFCC level in $\mathrm{S} 25 \mathrm{C}$, whereas above this level, the PIFCC level in 6061 will be higher than the RIFCC level in $\mathrm{S} 25 \mathrm{C}$.

We note also that as shown in Figures 2 and 3, for a specimen thickness of $0.3 \mathrm{~mm}$, the $9 \mathrm{Cr}-1 \mathrm{Mo}$ steel exhibits PIFCC, whereas at the same thickness, the 1018 steel exhibits RIFCC. The microstructure of the 1018 steel is much coarser than that of the temperedmartensitic microstructure of the $9 \mathrm{Cr} 1 \mathrm{Mo}$ steel, and as a result, the fracture surface of the 1018 steel is much rougher than that of the $9 \mathrm{Cr}-1 \mathrm{Mo}$ steel. In 6-mm-thick specimens, this greater roughness led to a RIFCC $K_{\text {opmax }}$ level of $4.25 \mathrm{MPa} \sqrt{\mathrm{m}}$ for the 1018 steel, whereas the RIFCC $K_{\text {opmax }}$ level for the 9Cr-1Mo steel was lower, i.e., $2.5 \mathrm{MPa} \sqrt{\mathrm{m}}$. However, at the $0.3-\mathrm{mm}$ thickness level, for the $9 \mathrm{Cr}-1 \mathrm{Mo}$ steel, the area of contact involved in PIFCC might be larger than that involved in RIFCC, and PIFCC dominates. In the case of the 1018 steel, because of the coarseness of the microstructure, RIFCC dominates even at the $0.3-\mathrm{mm}$ thickness level.

Finally, we note that the fall-off in the PIFCC closure level seen in Figure 4 for the aluminum alloy 2519 at the higher $\Delta \mathrm{K}$ levels may be due to the crushing of the surface residually stretched plastic regions during the unloading portion of a cycle.

\section{CONCLUSIONS}

As a result of the information garnered in this investigation, the following conclusions are reached:

1. All alloys exhibit two opening levels. One is associated with the plane-strain region of the crack front, and the other is associated with the surface, planestress region. The opening level is higher in the plane stress region.

2. The thickness of the specimen is an important factor. As the specimen thickness increases, the importance of RIFCC increases and that of PIFCC decreases.
3. The material factors that promote PIFCC are a low yield stress, a low Young's modulus, and a low rate of strain hardening. These factors promote a high CTOD and a high degree of lateral contraction at the notch tip, which is responsible for PIFCC.

4. A competition is observed between PIFCC and RIFCC as to which will dominate. In general, RIF$\mathrm{CC}$ will occur in most steels. However, in a steel with a fine microstructure, the roughness will be low and PIFCC may occur, as in the case of 0.3 -mm-thick specimens of $9 \mathrm{Cr}-1 \mathrm{Mo}$ steel.

\section{ACKNOWLEDGMENTS}

The authors express their thanks to Prof. Chobin Makabe of the University of the Ryukyus and to Prof. Hisao Matsunaga of Fukuoka University for helpful discussions throughout the course of this investigation.

\section{REFERENCES}

1. J.C. Newman and W. Elber, eds.: Mechanics of Fatigue Crack Closure, ASTM STP 982, American Society for Testing and Materials, West Conshohocken, PA, 1988.

2. R.C. McClung and J.C. Newman, eds.: Advances in Fatigue Crack Closure Measurement and Analysis, vol. 2, ASTM STP 1343, American Society for Testing and Materials, West Conshohocken, PA, 1999.

3. W. Elber: Eng. Fract. Mech., 1970, vol. 2, pp. 37-45.

4. W. Elber: In: Damage Tolerance in Aircraft Structures, ASTM STP 486, American Society for Testing and Materials, West Conshohocken, PA, 1971, pp. 230-42.

5. H. Bao: Ph.D. Dissertation, University of Connecticut, Storrs, CT, 1994.

6. K. Minakawa, G. Levan, and A.J. McEvily: Metall. Trans. A, 1986, vol. 17A, pp. 1787-95.

7. B. Budiansky and J. Hutchinson: J. Appl. Mech., 1978, vol. 45, pp. $267-76$.

8. M. Renauld: M.S. Thesis, University of Connecticut, Storrs, CT, 1993.

9. J. Schivje: In: Mechanics of Fatigue Crack Closure, ASTM STP 982, J. Newman and W. Elber, eds., American Society for Testing and Materials, West Conshohocken, PA, 1988, pp. 5-34.

10. A.J. McEvily: Fatigue Frac. Eng. Mat. Struct., 2009, vol. 32, pp. 284-85.

11. A.J. McEvily, D. Eifler, and E. Macherauch: Eng. Fract. Mech., 1991, vol. 40, pp. 571-84.

12. ASTM E399-90, Standard Test Method for Plane-Strain Fracture Toughness of Metallic Materials, 1991 Annual Book of ASTM Standards, pp. 500-02.

13. ASTM E399-90, Standard Test Method for Plane-Strain Fracture Toughness, Metallic Materials, 1991 Annual Book of ASTM Standards, pp. 506-09.

14. R. Bowman, S.D. Antolovich, and R.C. Brown: Eng. Fract. Mech., 1988, vol. 31, pp. 703-12.

15. ASTM E647-05, Standard Test Method for Measurement of Fatigue Crack Growth Rates, 2005 Annual Book of ASTM Standards, pp. 1-45.

16. A.J. McEvily, Jr.: Met. Sci., 1977, vol. 11 (8-9), p. 274

17. A.J. McEvily and Z. Yang: Met. Soc., 1987, pp. 3-12.

18. S. Ishihara and A.J. McEvily: Int. J. Fatigue, 2002, vol. 24, pp. 1169-74.

19. A.J. McEvily, S. Ishihara, M. Endo, H. Sakai, and H. Matsunaga: Int. J. Fatigue, 2007, vol. 29, pp. 2737-45.

20. A.J. McEvily, S. Ishihara, and M. Endo: Int. J. Fatigue, 2005, vol. 27, pp. 862-66.

21. D. Broek and J. Schijve: The Effect of Sheet Thickness on Fatigue Crack Propagation in 2024-T3 Alclad Sheet Material, NLR_ 
TRM2129, National Aerospace Laboratory, Amsterdam, The Netherlands, 1963.

22. T.C. Lindley and C.E. Richards: Mater. Sci. Eng., 1974, vol. 14, pp. 281-293.

23. S. Matsuoka and K. Tanaka: Eng. Fract. Mech., 1980, vol. 13, pp. 293-306.

24. D. Rhodes and J.C. Radon: Effect of Some Secondary Test Variables on Fatigue Crack Growth, Fracture Mechanics, 14th Symp., vol. 2: Testing and Applications, ASTM STP 791, ASTM, 1983, pp. II-33 to II-46.
25. Z. Yang and A.J. McEvily: Effects of Load and Thermal Histories, P.K. Liaw and T. Nicholas, eds., TMS, Warrendale, PA, 1987, pp. 3-12.

26. A.J. McEvily, S. Ishihara, and Y. Mutoh: Int. J. Fatigue, 2004, vol. 26, pp. 1311-19.

27. Z. Yang and A.J. McEvily: J. Mech. Behav. Mater., 1991, vol. 3 (2-3), pp. 85-102.

28. P.C. Paris and L. Hermann: In: Fatigue Thresholds, Fundamental and Engineering Applications, J. Backlund, A.F. Blom, and C.J. Beevers, eds., Engineering Materials Advisory Services, Worcester, U.K., 1981, pp. 1-33. 